ENCYCLOPÉDIE Encyclopédie berbère

BERBERE

6 | 1989

6 | Antilopes - Arzuges

\title{
Arbres sacrés
}

D. Champault

\section{OpenEdition}

Journals

Édition électronique

URL : http://journals.openedition.org/encyclopedieberbere/2577

DOI : 10.4000/encyclopedieberbere. 2577

ISSN : 2262-7197

\section{Éditeur}

Peeters Publishers

\section{Édition imprimée}

Date de publication : 1 janvier 1989

Pagination : 852-855

ISBN : 2-85744-324-2

ISSN : 1015-7344

\section{Référence électronique}

D. Champault, «Arbres sacrés », Encyclopédie berbère [En ligne], 6| 1989, document A259, mis en ligne le 01 décembre 2012, consulté le 13 octobre 2020. URL : http://journals.openedition.org/ encyclopedieberbere/2577; DOI : https://doi.org/10.4000/encyclopedieberbere.2577

Ce document a été généré automatiquement le 13 octobre 2020

(c) Tous droits réservés 


\section{Arbres sacrés}

\section{Champault}

1 Dans le paysage maghrébin, tout arbre de port et de taille exceptionnels était d'emblée défini comme "sacré » ou mrabet (marabout). Sujets isolés ou bosquet étaient presque toujours mis en relation avec un saint dont le plus souvent ils annexaient le nom; à moins que leur nom d'espèce précédé de Sidi ou de Lalla ne soient ainsi anobli. Plus rares ceux qui ne recevaient pour qualificatif qu'un euphémisme par litote : le «petit acacia, le « petit » tamaris... »

2 La croissance remarquable d'un arbre ne pouvait être attribuée qu'à la force de la bénédiction divine; le plus souvent cette force, la baraka, est véhiculée par un saint ; saint connu ou anonyme, que la croyance populaire fait vivre, à un moment de son histoire, en symbiose avec l'olivier, l'acacia, le caroubier ou l'éphédra... Au départ il s'agit fréquemment d'une halte sous un ombrage tutélaire, parfois n'excédant pas une journée, mais pouvant au contraire s'étendre sur toute une vie. L'arbre peut aussi naître et se développer au contact ou au voisinage d'une sépulture de saint, réelle ou supposée. Par une diffusion subtile, la baraka du saint (éventuellement une sainte) permet à l'arbre un développement et une longévité d'autant plus remarquables que ses voisins, apparemment dans les mêmes conditions climatiques, demeurent rabougris.

3 L'appartenance au sacré, une fois reconnue, devient très vite pour l'arbre une sauvegarde. Tout un rituel s'ordonne dont la finalité revient à préserver ses branches (les casser inconsidérément serait un attentat, en prélever pour faire du feu serait sacrilège), à maintenir le sol qu'il ombrage dans un état de propreté décent. Les femmes lui rendent des visites (comme à la tombe ou au cénotaphe d'un marabout authentique), à jour fixe avec le cérémonial convenable : encensements, petits tas de pierres en ex-voto (allumage de bougies ou de mèches dans l'huile d'un récipient rudimentaire) et aux grandes fêtes islamiques ou commémoratives des saints: procession d'hommes et de femmes, chants, tirs à la cible...

4 L'usage le plus fréquent qui perdure depuis des décennies et sans doute des siècles, est celui des ex-voto de chiffons. A l'occasion d'une visite pieuse, les femmes effrangent leur voile ou leur vêtement drapé pour en nouer un lambeau aux branches de l'arbre 
sacré. Elles matérialisent ainsi leur prière, ou leur vœu, et prolongent leur présence physique auprès du saint. Bientôt les modestes ex-voto seront dilacérés par le vent, décolorés par le soleil. Mais nul ne s'y trompe et ne s'aventurerait à dépouiller l'arbre de ses tristes haillons. C'est que, support de prière, le chiffon est aussi un nœud qui enferme le mal dont on veut se débarrasser.

Dans les zones sablonneuses où se trouvent en abondance des rétama (Genista R.), ce sont leurs longs rameaux que l'on peut voir noués à proximité d'une tombe réputée abriter la dépouille d'un saint.

De telles pratiques ne sont pas une spécificité du Maghreb: on les observe en bien d'autres points du globe sous des formes comparables ou voisines. Mais on ne saurait en aucun cas parler de "dendrolâtrie " : l'arbre n'est pas une divinité en lui-même, il n'est que le vecteur d'une force sacrée, depuis toujours sous-jacente, aujourd'hui véhiculée par les santons de l'Islam.

7 A moins qu'une particularité morphologique n'en fasse un arbre exceptionnel, différent, donc possiblement élu comme dépositaire de la baraka, un palmier productif n'est que rarement considéré comme "sacré ». Ses fruits, son bois, ses feuilles et ses fibres sont sans doute trop utiles à l'homme. En revanche, on peut trouver dans une palmeraie prospère un palmier, situé à l'écart, dont les fruits, jamais cueillis, sont dévolus aux jnun. Cet abandon propitiatoire sauvegarde le gros de la récolte. Les enfants apprennent très tôt à ne pas toucher aux dattes tombées et les abandonnent aux fourmis et autres insectes.

8 La suspicion révérencieuse qui s'attache à l'arbre des génies est à l'opposé de l'attitude des Maghrébins envers leurs arbres sacrés, tissée de confiance et d'affection. Les femmes particulièrement les entourent d'attentions lors des visites pieuses, soit qu'elles demandent, soit qu'elles remercient.

9 Les arbres sont les traits d'union entre l'invisible souterrain et l'inconnu céleste. Ils témoignent de la force diffuse et bénéfique qui assure la fertilité de la terre et rythme la croissance des végétaux. Leur valeur symbolique de résurrection est d'autant plus manifeste qu'ils sont le plus souvent liés à une tombe.

10 Ces notions touchant au sacré, diffuses dans la thèse frazérienne, n'ont guère été révisées par les anthropologues modernes, d'où l'ancienneté des références bibliographiques disponibles. Et cependant les arbres sacrés n'appartiennent pas à un passé révolu. 


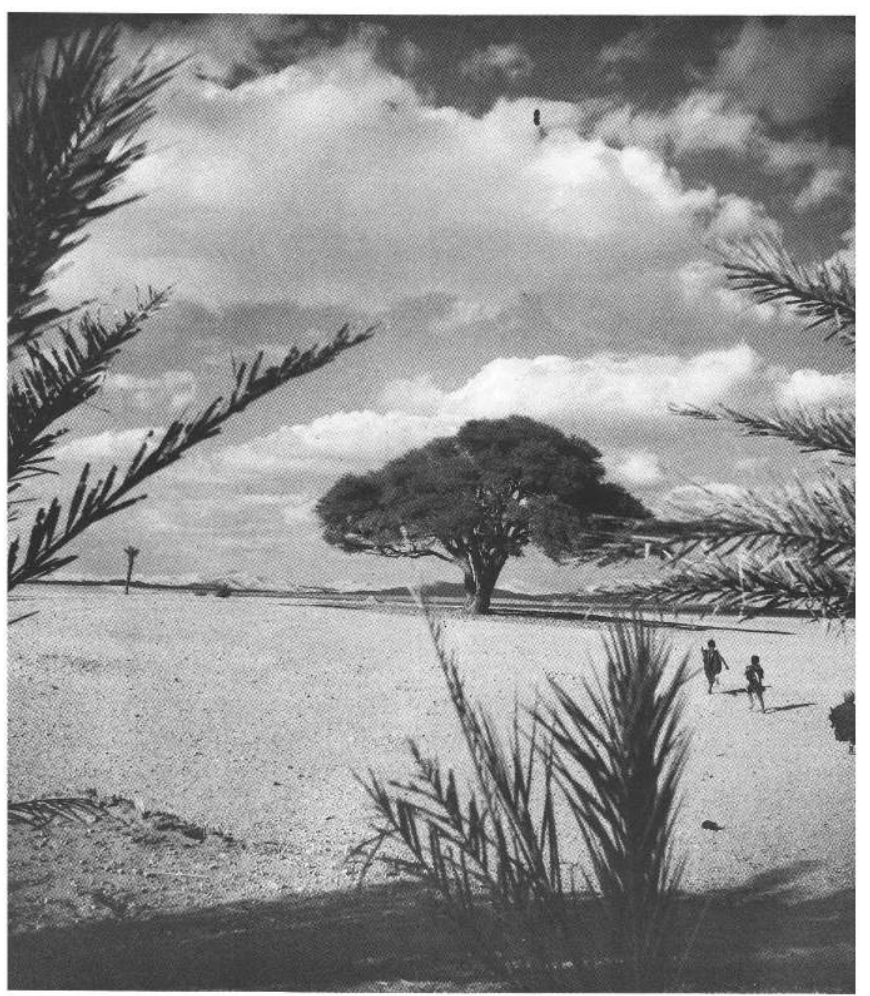

L'arbre doit sa taille exceptionnelle à la bénédiction du saint. La tradition veut que les assemblées de saints venus de tous les points du monde musulman se réunissent hebdomadairement sous ses branches. Un culte régulier lui est rendu : circumambulations, tir à la cible (hommes) encensement (femmes). Au pied de l'arbre, sur la gauche, l'on distingue un petit tumulus, autel rustique où l'on brûle de l'encens et allume les bougies.(Photo D. Champault.)

11 En janvier 1985, j'ai assisté à " l'investiture » d'un jeune acacia à la lisière d'un des ksour de Tabelbala (Saoura). Un vieillard muet, venant de l'Ouest, monté sur un chameau blanc, avait choisi son ombre pour y camper pendant une quinzaine de jours. Il vécut de la charité publique, faisant ses cinq prières quotidiennes sur place, sans jamais se rendre à la mosquée. Le chameau, entravé, se nourrissait à proximité. Un matin le vieillard et sa monture disparurent sans que l'on puisse suivre leurs traces. Le jour même, les femmes voisines firent irruption sur les lieux, brûlant de l'encens sur un autel de fortune, partageant des collations... Un santon anonyme, matérialisé dans l'acacia, venait de naître.

\section{BIBLIOGRAPHIE}

DALLET J., « Mzaras de Kroumirie », IBLA, 1939, pp. 323-342.

DEMEERSEMAN R. P., « Le culte des walis en Kroumirie », IBLA, 1964, pp. 119-166.

DERMENGHEM E., Le culte des saints dans l'Islam maghrébin, Paris, Gallimard, 1954. 
DOUTTE E., Marrakech, Comité du Maroc, Paris, 1905, pp. 92-93.

ID., La société musulmane du Maghreb. Magie et religion dans l'Afrique du Nord, Alger, Jourdan 1909, pp. 436-438.

SERVIER J., Les portes de l'année, Paris, R. Laffont, 1962.

INDEX

Mots-clés : Magie, Rite 